\title{
Prevalence and persistent use of psychotropic drugs in older adults receiving domiciliary care at baseline
}

\author{
Marie Turmo Lornstad ${ }^{1 *}\left(\mathbb{D}\right.$, Marte Aarøen ${ }^{1+}$, Sverre Bergh ${ }^{2}$, Jūrate Šaltytè Benth ${ }^{3}$ and Anne-Sofie Helvik ${ }^{4}$
}

\begin{abstract}
Background: Little is known about the use of psychotropic drugs in older adults receiving domiciliary care. The first aim was to describe the prevalence and persistency of use of psychotropic drugs in older adults ( $\geq 70$ years) with and without dementia receiving domiciliary care. Furthermore, the second aim was to explore factors associated with persistent drug use at two consecutive time-points. Lastly, we aimed to examine if use of psychotropic drugs changed after admission to a nursing home.
\end{abstract}

Methods: In total, 1001 community-dwelling older adults receiving domiciliary care at inclusion participated in the study. Information about psychotropic drug use was collected at baseline, after 18 months and after 36 months. The participants' cognitive function, neuropsychiatric symptoms (NPS) and physical health were assessed at the same assessments. Participants were evaluated for dementia based on all gathered information. Formal level of care (domiciliary care or in a nursing home) was registered at the follow-up assessments.

Results: Prevalence and persistent use of psychotropic drugs in older adults receiving domiciliary care was high. Participants with dementia more often used antipsychotics and antidepressants than participants without dementia. The majority of the participants using antipsychotic drugs used traditional antipsychotics. Younger age was associated with higher odds for persistent use of antipsychotics and antidepressants, and lower odds for persistent use of sedatives. Severity of NPS was associated with persistent use of antidepressants. The odds for use of antipsychotics and antidepressants were higher in those admitted to a nursing home as compared to the community-dwelling participants at the last follow-up.

Conclusion: There was a high prevalence and persistency of use of psychotropic drugs. The prevalence of use of traditional antipsychotics was surprisingly high, which is alarming. Monitoring the effect and adverse effects of psychotropic drugs is an important part of the treatment, and discontinuation should be considered when possible due to the odds for severe adverse effects of such drugs in people with dementia.

Keywords: Cognitive impairment, Elderly, Home care, Medication, Long term care, Transferral

\section{Background}

Prevalence of psychotropic drug use is high in older adults (> 70 years) $[1,2]$. It is known that the prescription rate of psychotropic drugs in western countries increases with higher age $[3,4]$, and community-dwelling older adults are prescribed approximately half of all

\footnotetext{
* Correspondence: marietl@stud.ntnu.no

Marie Turmo Lornstad and Marte Aarøen have contributed equally to this article.

${ }^{1}$ Department of Public Health and Nursing, Norwegian University of Science and Technology (NTNU), Postbox 8905, N-7491 Trondheim, Norway
} Full list of author information is available at the end of the article psychotropic drugs prescribed in Norway [4]. A review of 67 studies from the USA concluded that one in four older adults used psychotropic drugs with an abuse or dependency potential (e.g. benzodiazepines) [3]. The prevalence of use of anxiolytics and sedatives increase with age in older adults [5].

In community-dwelling older adults, people with dementia more often use psychotropic drugs than those without dementia [6, 7]. Neuropsychiatric symptoms (NPS) following dementia are very common in community-dwelling older adults receiving domiciliary

(C) The Author(s). 2019 Open Access This article is distributed under the terms of the Creative Commons Attribution 4.0 International License (http://creativecommons.org/licenses/by/4.0/), which permits unrestricted use, distribution, and 
care and in nursing home residents $[8,9]$. Chan et al. reported that in a group of community-dwelling older adults, a clinical diagnosis of dementia, but not the severity of NPS, was associated with the use of psychotropic drugs [10]. Nursing home residents with dementia more often use antipsychotics than residents without dementia [11-13], and the severity of their NPS is associated with persistent use of psychotropic drugs [14]. However, non-pharmacological interventions should be the first-choice treatment of NPS in dementia [15-18], but with severe NPS psychotropic drug use may be unavoidable.

Antipsychotics are commonly used to treat agitation in older adults with dementia, for example a recent study reported the prevalence of antipsychotic use to be $38 \%$ [18]. There is little evidence that long term use of antipsychotics is effective in the management of NPS in older adults with dementia, but it may have adverse effects [19], e.g. higher risk of cerebrovascular events $[20,21]$, increased risk of falling [22, 23] and a higher risk of mortality [24, 25]. Atypical antipsychotics are known to have less extrapyramidal side-effects than traditional antipsychotics [26], but they are also associated with a higher risk of hip fractures and a higher risk of mortality in patients with dementia [27, 28]. Antidepressants and benzodiazepines may also cause serious short- and long-term adverse effects, e.g. increase in falls [22, 29-31]. While prevalence and persistency of psychotropic drugs in nursing home residents have been studied and found to be high $[9,14]$, it remains to be studied whether persistent use of psychotropic drugs in older adults receiving domiciliary care is related to having dementia and NPS.

Studies have found that the strongest indicators for nursing home admission are functional impairment, cognitive impairment and older age [32-35]. It is known that older adults in nursing homes frequently are prescribed psychotropic drugs [9, 14, 36]. There might be changes in prescription of drugs after admission to nursing home, especially when it comes to psychotropic drugs [36]. One British longitudinal study has linked information about psychotropic drug use in older adults to transition to a nursing home, and found psychotropic drugs to be prescribed more often after admission to a nursing home than among those who continue to live at home [37], but the study did not adjust for dementia and other health conditions. To our knowledge, there are few studies on prescription of psychotropic drugs following admission to long-term nursing home care [36, 37].

Thus, the first aim of the present study was to describe the prevalence of psychotropic drug use in persons $\geq 70$ years with or without dementia receiving in-home domiciliary care: at the baseline of the study, after 18 months and after 36 months. The second aim was to assess the persistency in use of psychotropic drugs, and explore factors possibly associated with such persistency, i.e. severity of dementia, degree of NPS, physical health and/ or nursing home-admission. The third aim was to explore whether admission to a nursing home, was associated with use of these drugs adjusting for severity of dementia, NPS and physical health.

\section{Methods \\ Study design}

This is a longitudinal study with a 36-month follow-up period. The baseline data was collected between August 2008 and December 2010. Follow-up assessments were conducted 18 months and 36 months after baseline-assessment.

\section{Participants}

1796 persons (age $\geq 70$ years) from 19 municipalities in the eastern part of Norway were invited to participate in the study. We chose participants over the age of 70 , as it in Norway, and internationally, has been discussed changing the limit for being an "old adult" from 65 years or older, to 70 years or older [38]. The participants had to be community-dwelling and receiving domiciliary care from the municipality at inclusion. The amount and kind of service received were not important. Those eligible for inclusion had to have a next of kin who saw them at least once every week. Both established recipients and new recipients of domiciliary care were included. New recipients were recruited successively. The participants were recruited from municipalities of various sizes, both rural and urban.

Of the total 1796 invited persons, 795 declined to participate in the study. Thus, 1001 persons were included. Those who declined were more often women and older than those who participated in the study [8].

\section{Measures}

The use of drugs was registered from the participants' medical records. Drugs were divided into groups according to the Anatomical Therapeutic Chemical (ATC) Classification System. Psychotropic drugs were categorized into; antipsychotics (N05A except lithium), anxiolytics (N05B), hypnotics/sedatives (N05C), antidepressants (N06A), and anti-dementia drugs (N06D). Use of drugs was dichotomized into yes or no. There were no participants with missing information about use of drugs. Dosage of drugs was not available in the present study.

Physical morbidity was evaluated using the General Medical Health Rating Scale (GMHR), considering the patients number and severity of medical conditions and the use of drugs due to these conditions. GMHR is 
scored from 1 to 4 , where 1 indicates very poor physical health and 4 indicates good physical health [39].

The personal activities of daily living (P-ADL) were measured by the Physical Self-Maintenance Scale (PSMS), evaluating six different basal needs. Each PSMS item is scored from 1 to 5 , where higher scores indicate lower P-ADL function [40].

Cognitive function and dementia severity symptoms were evaluated by the following tools: Mini-Mental State Examination (MMSE), Clock-Drawing Test (CDT), the Informant Questionnaire on Cognitive Decline in Elderly (IQ-CODE) and Clinical Dementia Rating scale (CDR). MMSE is a standardized test of cognitive function that is scored from 0 to 30 points. Higher scores indicate good cognitive function [41]. The Clock Drawing Test is scored from 0 to 5 . A perfect clock is scored 5 [42]. In the Informant Questionnaire on Cognitive Decline in Elderly (IQ-CODE), the next of kin assesses the change in cognitive function during the last decade. The scoring scale goes from 0 to 5 . A score $<3$ indicates improvement, $>3$ indicates decline and a score of 3 indicates no change in cognitive function [43]. The CDR includes six domains; memory, orientation, judgment and problem solving, community affairs, home functions, and personal care. An algorithm gives a total score of 0, 0.5, 1, 2 or 3 , indicating respectively; no dementia, possible dementia, and mild, moderate and severe dementia [44]. In the present study, we used CDR sum of boxes (CDR-SoB), with a point score ranging from 0 to 18 , where a higher score indicates higher severity of dementia [45]. The assessment tools for cognitive function and severity of dementia have been translated and validated in Norwegian [46-48].

Neuropsychiatric symptoms (NPS) were evaluated using the 10-item Neuropsychiatric Inventory (NPI) [49] in a translated Norwegian version [50]. The following 10 symptoms are covered: delusion, hallucination, euphoria, agitation/aggression, disinhibition, irritability/lability, depression/dysphoria, anxiety, apathy/indifference, and aberrant motor behaviour. Each symptom was rated by the next of kin based on its occurrence the previous four weeks.

Dementia was diagnosed independently by two experienced physicians in geriatric psychiatry at all three assessments based on all available information. Dementia was diagnosed according to the ICD-10 criteria [51]. In cases of disagreement, consensus was reached after consulting a third clinical expert.

The formal level of care at the follow-up assessments was registered as location, i.e. community-dwelling receiving domiciliary care or living in a nursing home. Type of home support at baseline was registered as nursing care, domestic help and/or other types of support such as food delivery, day care centre and safety alarm. Demographic data including age, gender, municipality of residence and marital status were registered in the baseline assessment.

\section{Procedure}

The process of collecting data material was led by a research nurse that cooperated with the assessors in the different municipalities. The majority of the assessors were nurses, social educators and occupational therapists. All the assessors had a two-day course of training on how to use the assessments scales before the baseline data collection. A one-day training course was conducted prior to the second and third assessment. The participants and their next of kin were interviewed simultaneously by two separate assessors.

\section{Data analysis}

Sample characteristics at baseline were presented as means and standard deviations or as frequencies and percentages. Participants with dementia and participants without dementia were compared. Prevalence and persistence of medical drugs by dementia/no dementia and admission to nursing home/living at home were presented as percentages. Due to participants belonging to municipality, data might exhibit hierarchical structure. Therefore, groups of participants were compared by linear mixed model (for continuous data) or generalized linear mixed model (for categorical data) with fixed effects for dementia status and random intercepts for municipality, if necessary.

The use of each defined category of psychotropic drugs given use one or two time-points earlier (Lag 1 and Lag 2, respectively) was assessed by a generalized linear mixed model with random intercepts for municipality. The dependent variable was use of the given psychotropic drugs at A2 or A3, while the independent variable was use of the same category of psychotropic drugs at baseline. Each model was adjusted for pre-defined covariates measured at baseline (age, sex, marital status, CDR, GMHR, PSMS, affective NPS, psychosis NPS and agitation NPS) and then reduced for excessive covariates by applying Akaike's Information Criteria (AIC) [52], where a lower value indicates a better model.

To assess factors associated with persistent use of each category of psychotropic drugs, a generalized linear mixed model with random effects for patients nested within municipality was estimated. Dependent variable was defined as persistent use if the given category of psychotropic drugs was used at two consecutive time-points. Adjustment for covariates measured at a previous time-point was performed. Relative importance of each covariate in the adjusted models was determined from standardized regression coefficients. In addition, effect of location on use of psychotropic drugs at the same 
time-point was assessed by estimating the model with random effects for patients nested within municipality and fixed effects for location and interaction between time and location. The results were adjusted for covariates measured at baseline (age, gender) or at the same time-point (health measures and marital status). The results in the adjusted models were presented as odds ratio (OR) and 95\% confidence intervals (CI).

The data was analysed in SPSS version 24 and SAS version 9.4. All tests were two-sided. Results with $p$-values below 0.05 were considered statistically significant.

\section{Results}

\section{Sample characteristics}

As shown in Table 1, the mean (SD) age of the total sample of 1001 participants at baseline was 83.4 (5.7) years, $683(68.2 \%)$ were female and 703 (70.2\%) were single or a widow/widower. Of the participants, 599 (59.8\%) were assessed at the second assessment
(A2), and $456(45.5 \%)$ were available for the third assessment (A3) (Fig. 1). At A2 and at A3, 89 (14.9\%) and $114(25.2 \%)$ had been admitted to a nursing home, respectively.

\section{Prevalence of psychotropic drugs by dementia and place of living}

The prevalence of psychotropic drug use is presented in Table 2. Sedatives were the most frequently used drugs at all time-points (varying between 21 and 23\%). Antipsychotics were the least frequently used types of psychotropic drug, being $4 \%$ at the first (A1) and $7 \%$ at the last time-point (A3). The majority of the participants using antipsychotics used traditional antipsychotics, and traditional antipsychotics were also more frequently used by participants with dementia than by participants without dementia at all time-points. The prevalence of use of antidepressants was approximately $16 \%$ at A1, and $22 \%$ at A3. The prevalence of use of any psychotropic drug

Table 1 Sample characteristics at baseline

\begin{tabular}{|c|c|c|c|c|c|}
\hline & & Total $(N=1001)$ & Dementia $(N=415)$ & No dementia $(N=586)$ & $p$-value \\
\hline \multicolumn{6}{|l|}{ Socio-demographics } \\
\hline Age & Mean (SD) & $83.4(5.7)$ & $84.5(5.6)$ & $82.6(5.6)$ & $<0.001^{a}$ \\
\hline Females & N (\%) & $683(68.2)$ & $273(65.8)$ & $410(70.0)$ & $0.171^{b}$ \\
\hline Married & N (\%) & $297(29.7)$ & $131(31.6)$ & $166(28.4)$ & $0.250^{b}$ \\
\hline \multicolumn{6}{|l|}{ Health condition } \\
\hline \multicolumn{6}{|l|}{$\mathrm{GMHR}^{\mathrm{d}}$} \\
\hline Good & N (\%) & $155(15.5)$ & $43(10.4)$ & $112(19.1)$ & $<0.001^{b}$ \\
\hline Fairly Good & N (\%) & $392(39.2)$ & $147(35.5)$ & $245(41.9)$ & \\
\hline Poor & N (\%) & $346(34.6)$ & $166(40.1)$ & $180(30.8)$ & \\
\hline Very Poor & N (\%) & $106(10.6)$ & $58(14.0)$ & $48(8.2)$ & \\
\hline PSMS & Mean (SD) & $9.2(3.5)$ & $10.9(4.0)$ & $7.9(2.6)$ & $<0.001^{a}$ \\
\hline NPI Agitation sub-syndrome $e^{f}$ & Mean (SD) & $1.6(4.4)$ & $2.6(5.7)$ & $0.9(2.9)$ & $<0.001^{a, c}$ \\
\hline NPI Psychosis sub-syndrome ${ }^{g}$ & Mean (SD) & $0.5(2.0)$ & $1.1(2.8)$ & $0.2(1.1)$ & $<0.001^{a, c}$ \\
\hline NPI Affective sub-syndrome ${ }^{h}$ & Mean (SD) & $2.9(5.3)$ & $4.8(6.8)$ & $1.6(3.3)$ & $<0.001^{\mathrm{a}}$ \\
\hline No of drugs & Mean (SD) & $5.3(2.9)$ & $5.4(3.0)$ & $5.3(2.9)$ & $0.699^{a}$ \\
\hline \multicolumn{6}{|l|}{ Type of domiciliary care ${ }^{i}$} \\
\hline Nursing care & N (\%) & $670(67.4)$ & $347(84.0)$ & $323(55.6)$ & $<0.001^{b}$ \\
\hline Domestic help & N (\%) & $528(53.1)$ & $210(50.8)$ & $318(54.7)$ & 0.229 \\
\hline Other types of support & N (\%) & $599(59.8)$ & $272(65.5)$ & $327(55.8)$ & $0.001^{b}$ \\
\hline
\end{tabular}

Agitation sub-syndrome: Agitation/aggression, euphoria, disinhibition, irritability/lability, aberrant motor behavior. Psychosis sub-syndrome: Delusions, hallucinations

Affective sub-syndrome: Depression/dysphoria, anxiety, apathy/indifference

GMHR General Medical Health Rating, PSMS Physical Self-Maintenance Scale, NPI Neuropsychiatric Inventory

a Linear mixed model

${ }^{\mathrm{b}}$ Generalized linear mixed model

${ }^{c}$ No cluster effect on municipality level

${ }^{\mathrm{d}}$ Missing information in 2 participants

${ }^{\mathrm{e}}$ Missing information in 5 participants

${ }^{\mathrm{f}}$ Missing information in 35 participants

${ }^{9}$ Missing information in 26 participants

${ }^{\mathrm{h}}$ Missing information in 29 participants

'Missing information in 7 participants 


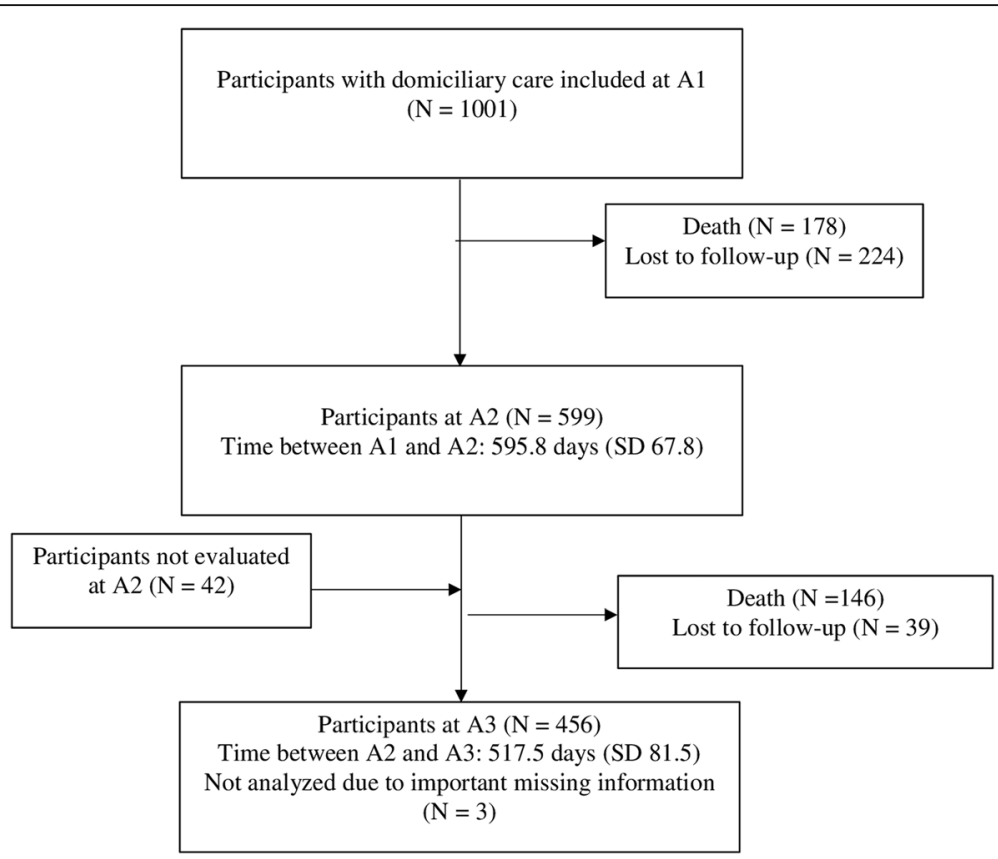

Fig. 1 Flow chart of participants from baseline (A1) to last follow-up (A3) with a mean (SD) follow-up time at each assessment

was high in all three assessments. Antipsychotics, antidepressants and anti-dementia drugs were more frequently used in those with dementia than in those without dementia at all time-points. Furthermore, we found the prevalence of use of all types of psychotropic drugs, except from sedatives at A2, to be higher in those admitted to a nursing home than in those living at home at A2 and A3 (Table 3).

\section{Persistent use of psychotropic drugs by dementia}

The persistent use of psychotropic drugs was high for all types of psychotropic drugs from A1 to A2 and from A2 to A3, both in participants with and without dementia (Table 2). Persistent use of any psychotropic drug was over $80 \%$ for the total sample, and it was higher between A1 and A2 in participants with dementia than in participants without dementia.

Odds for use of psychotropic drugs at one time-point, given use of the same type of psychotropic drug at earlier time-points, are presented in Table 4. In general, the odds for persistent use were highest when compared with the nearest time-point ( $\operatorname{Lag} 1$ ), but lower when compared to two time-points earlier (Lag 2). The adjusted OR for use of antipsychotics decreased the most, from $80.5(28.9 ; 224.0)$ to $20.8(5.8 ; 75.0)$, but the odds for the other drugs were also markedly reduced.

\section{Factors associated with persistent use of psychotropic} drugs at two consecutive time-points

In the adjusted analysis, an increased severity of affective sub-syndrome of NPI, lower P-ADL function (higher
PSMS), admission to nursing home and younger age were associated with higher odds for persistent use of antidepressants (Table 5). Furthermore, younger age was associated with higher odds for persistent use of antipsychotics, and lower odds for persistent use of sedatives. Female gender and lower P-ADL function were associated with higher odds for persistent use of anxiolytics.

\section{Effect of location on use of psychotropic drugs at the same time-point}

The results of effect of time and location on use of psychotropic drugs are presented in Fig. 2. In the adjusted analysis, the odds for use of antipsychotics and antidepressants were higher in those admitted to a nursing home as compared to the community-dwelling participants at A3. Please see Additional file 1: Tables S1 and S2 for further details.

More severe dementia and higher affective sub-syndrome scores, lower age and female gender were associated with higher odds for use of antidepressants (Additional file 1: Table S1). Higher affective sub-syndrome and female gender were also associated with higher odds for use of anxiolytics. Covariates associated with higher odds for use of sedatives were lower P-ADL function and increasing age, whereas good physical health (higher GMHR) decreased the odds for use of sedatives.

\section{Discussion}

This follow-up study including 1001 community-dwelling older adults ( $\geq 70$ years) receiving domiciliary care at 
Table 2 Prevalence and persistence in use of psychotropic drugs

\begin{tabular}{|c|c|c|c|c|c|c|}
\hline & \multicolumn{6}{|c|}{ Prevalence n (\%) } \\
\hline & \multicolumn{2}{|l|}{$\mathrm{A} 1$} & \multicolumn{2}{|l|}{$\mathrm{A} 2$} & \multicolumn{2}{|l|}{ A3 } \\
\hline & All & $\mathrm{D} / \mathrm{nD}$ & All & $\mathrm{D} / \mathrm{nD}$ & All & $\mathrm{D} / \mathrm{nD}$ \\
\hline & $(N=1001)$ & $(\mathrm{N}=415 / 586)$ & $(N=599)$ & $(N=304 / 295)$ & $(N=453)$ & $(N=227 / 226)$ \\
\hline \multicolumn{7}{|l|}{ Psychotropic drug use } \\
\hline Antipsychotics (AP) & $36(3.6)$ & $24 / 12(5.8 / 2.0)^{* *}$ & $28(4.7)$ & $22 / 6(7.2 / 2.0)^{* *}$ & $30(6.6)$ & $26 / 4(11.5 / 1.8)^{* * *}$ \\
\hline Traditional AP & $31(3.1)$ & $19 / 12(4.6 / 2.0)^{*}$ & $23(3.8)$ & $17 / 6(5.6 / 2.0)^{*}$ & $23(5.1)$ & $19 / 4(8.4 / 1.8)^{* *}$ \\
\hline Atypical AP & $5(0.5)$ & $5 / 0(1.2 / 0)$ & $6(1.0)$ & $6 / 0(2.0 / 0)$ & $8(1.8)$ & $8 / 0(3.5 / 0)$ \\
\hline Antidepressants & $155(15.5)$ & $82 / 73(19.8 / 12.5)^{* *}$ & $121(20.2)$ & $80 / 41(26.3 / 13.9)^{* * *}$ & $101(22.3)$ & $70 / 31(30.8 / 13.7)^{* * *}$ \\
\hline Anxiolytics & $86(8.6)$ & 43/43 (10.4/7.3) & $71(11.9)$ & $48 / 23(15.8 / 7.8)^{* *}$ & $53(11.7)$ & $35 / 18(15.4 / 8.0)^{*}$ \\
\hline Sedatives & $221(22.1)$ & $103 / 118(24.8 / 20.1)$ & $128(21.4)$ & $78 / 50(25.7 / 16.9)^{*}$ & $103(22.7)$ & $59 / 44(26.0 / 19.5)$ \\
\hline Anti-dementia drugs & $57(5.7)$ & $53 / 4(12.8 / 0.7)^{* * * *}$ & $60(10.0)$ & $57 / 3(18.8 / 1.0)^{* * *}$ & $34(7.5)$ & $31 / 3(13.7 / 1.3)^{* * *}$ \\
\hline \multirow[t]{4}{*}{ Any PTD } & $403(40.3)$ & 208/195 $(50.1 / 33.3)^{* * *}$ & $272(45.4)$ & $178 / 94(58.6 / 31.9)^{* * *}$ & $210(46.4)$ & $132 / 78(58.1 / 34.5)^{* * *}$ \\
\hline & \multicolumn{6}{|c|}{ Persistence n (\%) } \\
\hline & \multicolumn{3}{|l|}{$\mathrm{A} 1-\mathrm{A} 2$} & \multicolumn{3}{|l|}{$\mathrm{A} 2-\mathrm{A} 3$} \\
\hline & All & $\mathrm{D} / \mathrm{nD}$ & & All & $\mathrm{D} / \mathrm{nD}$ & \\
\hline \multicolumn{7}{|l|}{ Psychotropic drug use } \\
\hline Antipsychotics (AP) & $17(63.0)^{\mathrm{a}}$ & $12 / 5(63.2 / 62.5)$ & & $13(65.0)^{\mathrm{a}}$ & \multicolumn{2}{|c|}{ 10/3 (62.5/75.0) } \\
\hline Traditional AP & $13(54.2)$ & $8 / 5(50.0 / 62.5)$ & & $11(64.7)$ & \multicolumn{2}{|c|}{$8 / 3(61.5 / 75.0)$} \\
\hline Atypical AP & $3(100)$ & $3 / 0(100 / 0)$ & & $1(25.0)$ & \multicolumn{2}{|c|}{$1 / 0(25.0 / 0)$} \\
\hline Antidepressants & $83(82.2)$ & 45/38 (83.3/80.9) & & $69(82.1)$ & \multicolumn{2}{|c|}{ 41/28 (80.4/84.8) } \\
\hline Anxiolytics & $29(63.0)$ & $17 / 12(70.8 / 54.5)$ & & $22(57.9)$ & \multicolumn{2}{|c|}{ 14/8 (53.8/66.7) } \\
\hline Sedatives & $77(66.4)$ & $37 / 40(68.5 / 64.5)$ & & $52(67.5)$ & \multicolumn{2}{|c|}{$27 / 25(71.1 / 64.1)$} \\
\hline Anti-dementia drugs & $26(74.3)$ & $24 / 2(75.0 / 66.7)$ & & $22(66.7)$ & \multicolumn{2}{|c|}{ 20/2 (64.5/100) } \\
\hline Any PTD & $191(81.3)$ & $106 / 85(86.9 / 75.2)^{*}$ & & $142(83.5)$ & \multicolumn{2}{|c|}{ 85/57 (85.9/80.3) } \\
\hline
\end{tabular}

A1: Assessment 1, at baseline

A2: Assessment 2, 18 months after baseline

A3: Assessment 3, 36 months after baseline

$D$ Dementia, $n D$ No dementia, PTD Psychotropic drugs

${ }^{*} p<0.05 ;{ }^{* *} p<0.01 ;{ }^{* * *} p<0.001 ; p$-values were calculated by generalized linear mixed model adjusting for municipality level if present

${ }^{a}$ One participant changed between traditional AP and atypical AP between assessments, which is why the numbers of persistent users of traditional AP plus persistent users of atypical AP does not equal persistent users of antipsychotics. This is the case for A1-A2 and A2-A3

baseline found that participants with dementia had higher prevalence of any psychotropic drugs than the participants without dementia. Additionally, the study revealed that those living in a nursing home at A3 had higher use of both antipsychotics and antidepressants, than the community-dwelling participants. Furthermore, persistent use of different types of psychotropic drugs was found to be high between the two consecutive assessments, both for participants with and without dementia. The persistent use diminished with longer time between assessments ( $\operatorname{Lag} 2)$.

\section{Use of antipsychotics}

In the present study, the prevalence of use of antipsychotics was $4 \%$ at A1 and 7\% at A3. The use of antipsychotics was higher in those with dementia than in those without dementia. This is in line with previous studies including community-dwelling participants [53, 54].
Antipsychotics should never be first line treatment in people with dementia $[17,18]$, because of the well-known adverse effects they can cause [17-19]. However, there might be cases where it is necessary to use antipsychotics when symptoms are severe and non-pharmacological treatments are not successful $[17,18]$. Unfortunately, we lack information about non-pharmacological treatments or efforts that have been tried prior to treatment with antipsychotics. Atypical antipsychotics are preferred in individuals with dementia rather than traditional antipsychotics, because of the adverse effects of traditional antipsychotics $[25,55,56]$. Even so, in the present study more than $2 / 3$ of all participants using antipsychotics used traditional antipsychotics, and the prevalence of use of both traditional and atypical antipsychotics did not change through our study in those with dementia.

Several participants were admitted to a nursing home during the follow-up period, and when adjusting for 
Table 3 Prevalence in use of psychotropic drugs according to nursing home admission

\begin{tabular}{lll}
\hline & $\begin{array}{l}\text { A2 } \\
\text { NHA/no NHA } \\
(N=89 / 510)\end{array}$ & $\begin{array}{l}\text { A3 } \\
\text { NHA/no NHA } \\
(N=114 / 339)\end{array}$ \\
\hline Psychotropic drug use & & \\
Antipsychotics (AP) & $11.2 / 3.5^{* *}$ & $18.4 / 2.7^{* * *}$ \\
Traditional AP & $7.9 / 3.1^{*}$ & $12.3 / 2.7^{* * *}$ \\
Atypical AP & $4.5 / 0.4^{* *}$ & $7.0 / 0$ \\
Antidepressants & $33.7 / 17.8^{* *}$ & $43.0 / 15.3^{* * *}$ \\
Anxiolytics & $20.2 / 10.4^{*}$ & $21.1 / 8.6^{* *}$ \\
Sedatives & $25.8 / 20.6$ & $32.5 / 19.5^{* *}$ \\
Anti-dementia drugs & $23.6 / 7.6^{* * *}$ & $20.2 / 3.2^{* * *}$ \\
Any PTD & $67.4 / 41.6^{* * *}$ & $73.7 / 37.2^{* * *}$ \\
\hline
\end{tabular}

A2: Assessment 2, 18 months after baseline

A3: Assessment 3, 36 months after baseline

NHA Nursing home admission, no NHA Living at home, PTD

Psychotropic drugs

${ }^{*} \mathrm{p}<0.05 ;{ }^{* *} \mathrm{p}<0.01 ;{ }^{* * *} \mathrm{p}<0.001 ; p$-values were calculated by generalized

linear mixed model adjusting for municipality level if present

differences in health measurements and demographics, there were elevated odds of using antipsychotics for participants that had become nursing home residents at A3. This is in line with another longitudinal study studying the transition to nursing home, and studies comparing people with dementia living in nursing homes and in the community-dwelling [36, 37, 57], However, these studies did not adjust for differences in physical health, severity of dementia and demographics between the groups. We do not have a firm explanation for the elevated use of antipsychotics in nursing home residents after adjustment for differences in health and demographics. However, it might be related to change in place of living and the stress and strain connected to transition to a nursing home [58, 59], and to the fact that nursing home residents have easier access to drug treatment than those living at home.

We found that a large percentage of participants who used antipsychotics at one time-point used the same type of drug at the following time-point. There were no differences between those with dementia and those without dementia with regard to persistent use of antipsychotics at two following time-points. This is interesting as antipsychotics, because of the mentioned side-effects, should only be used for a short period of time in people with dementia $[17,60]$. Also, it is well known that antipsychotics may have a limited effect on NPS in dementia $[61,62]$. The persistent use decreased when time between the two time-points increased to 36 months. This finding corresponds to the results in a longitudinal nursing home study [14]. We do not have further assessment time-points to add to our study, but it would have been interesting to explore the persistency further. We found no association between severity of psychosis sub-syndrome and use of antipsychotics at one time-point, or at two consecutive time-points. If there is no association between NPS and persistent use of antipsychotics, discontinuation should be considered in older adults with dementia. Other studies have found that antipsychotics might be discontinued without a significant increase in NPS [63]. Even so, there is need for evaluation and follow-up subsequent a discontinuation due to the risk of increased NPS after discontinuation [64].

\section{Use of antidepressants}

In the present study, approximately $16 \%$ at $\mathrm{A} 1$ and $22 \%$ at A3 used antidepressants. In Norway antidepressants are commonly used in older adults, both in community dwelling and nursing home residents, and more often in females [65]. We found that the participants with dementia used antidepressants more frequently than those without dementia at all time-points and in the adjusted analysis, we found those with more severe dementia to be more likely to use antidepressants than those with less severe dementia. Furthermore, in those with more severe affective NPS the odds were higher when it came to the use of antidepressants, which was expected [66, 67]. Depressive symptoms are common in older adults with dementia [68]. However, the efficacy of antidepressant treatment of depression in people with dementia is uncertain [69]. In addition, discontinuation of antidepressants may reduce NPS and depressive symptoms in individuals with dementia [69] and are tolerated in most cases (85\%) [70]. However, with discontinuation of antidepressants in participants with dementia it is essential that they are systematically and carefully monitored to identify those with increasing depressive symptoms [70].

In the adjusted analysis, nursing home residents had higher use of antidepressants at A3 compared to the community-dwelling participants at the same time-point, as reported by others [57]. Entry to nursing home may as previously mentioned increase the stress and strain on the residents and thus increase the odds for use of antidepressants, but in addition the availability to such treatment when indicated may be better than in the community-dwelling.

Not only the prevalence, but also the persistent use of antidepressants was high, both in those with and without dementia. In line with the results from a nursing home study [14], the present study found that higher severity of affective symptoms increased the odds for persistent use of antidepressants. Furthermore, we found that lower P-ADL function increased the odds for persistent use of antidepressants. We do not have a firm explanation, but it might be that those with lower P-ADL function, due to the situation of being more dependent on 
Table 4 OR for use of each category of psychotropic drugs at one time-point given use one or two time-points earlier, respectively, lag 1 and lag 2, covariates were measured at baseline

\begin{tabular}{|c|c|c|c|c|c|c|}
\hline \multirow[t]{2}{*}{ Variable } & \multicolumn{2}{|c|}{ Number of users } & \multicolumn{2}{|l|}{ Unadjusted } & \multicolumn{2}{|l|}{ Adjusted $^{\mathrm{b}}$} \\
\hline & Baseline & $\mathrm{A} 2$ & OR (95\% Cl) & $p$-value & OR (95\% Cl) & $p$-value \\
\hline \multicolumn{7}{|l|}{$\operatorname{Lag} 1\left(N=565^{a}\right)$} \\
\hline Antipsychotics ${ }^{c}$ & 26 & 27 & $76.8(28.5 ; 207.2)$ & $<0.001$ & $80.5(28.9 ; 224.0)$ & $<0.001$ \\
\hline Antidepressants $^{d}$ & 97 & 118 & $53.3(28.6 ; 90.1)$ & $<0.001$ & $47.3(25.1 ; 89.1)$ & $<0.001^{p}$ \\
\hline Anxiolytics ${ }^{e}$ & 44 & 67 & $25.9(12.0 ; 55.5)$ & $<0.001$ & $23.6(10.7 ; 52.1)$ & $<0.001$ \\
\hline Sedatives $^{f}$ & 109 & 118 & $17.3(10.5 ; 28.6)$ & $<0.001$ & $18.2(10.9 ; 30.4)$ & $<0.001$ \\
\hline \multicolumn{7}{|l|}{$\operatorname{Lag} 2\left(\mathrm{~N}=432^{\mathrm{a}}\right)$} \\
\hline & Baseline & $\mathrm{A} 3$ & & & & \\
\hline Antipsychoticsi & 17 & 29 & $24.2(7.1 ; 83.1)$ & $<0.001$ & $20.8(5.8 ; 75.0)$ & $<0.001$ \\
\hline Antidepressants $^{j}$ & 66 & 97 & $29.8(15.0 ; 59.2)$ & $<0.001$ & $28.1(13.8 ; 57.4)$ & $<0.001^{\mathrm{P}}$ \\
\hline Anxiolytics ${ }^{k}$ & 32 & 50 & $10.4(4.5 ; 23.9)$ & $<0.001$ & $11.4(4.5 ; 28.7)$ & $<0.001$ \\
\hline Sedatives' & 74 & 98 & $6.6(3.8 ; 11.3)$ & $<0.001$ & $6.6(3.8 ; 11.4)$ & $<0.001$ \\
\hline
\end{tabular}

Lag 1: Two consecutive assessment time points (baseline and A2)

Lag 2: One time point between selected time points (baseline and A3)

${ }^{\text {a }}$ Cases with at least one missing on covariates were excluded

${ }^{b}$ Following adjustment variables considered: Age, gender, marital status, CDR-SoB, GMHR, PSMS, NPI Affective sub-syndrome, NPI Psychosis sub-syndrome, NPI Agitation sub-syndrome all measured at A1 (baseline); Nursing home admission was not included as adjustment variable (no baseline values available); both models reduced by AIC

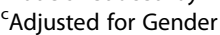

${ }^{\mathrm{d}}$ Adjusted for CDR-SoB and NPI Affective sub-syndrome

${ }^{\text {e}}$ Adjusted for PSMS and NPI Affective sub-syndrome

${ }^{f}$ Adjusted for NPI Affective sub-syndrome and NPI Agitation sub-syndrome

${ }^{\mathrm{g}}$ Adjusted for PSMS

${ }^{\mathrm{h}}$ Adjusted for CDR-SoB and NPI Psychosis sub-syndrome

iAdjusted for Gender and PSMS

jAdjusted for CDR-SoB, NPI Affective sub-syndrome and NPI Psychosis sub-syndrome

${ }^{k}$ Adjusted for Marital status, GMHR and NPI Affective sub-syndrome

'Adjusted for Age and CDR-SoB

${ }^{m}$ Adjusted for Marital status and CDR-SoB

${ }^{n}$ Adjusted for Gender, Age, Marital status and CDR-SoB

${ }^{\circ} p$-values were calculated by generalized linear mixed model adjusting for municipality level if present

$p$ no cluster effect at municipality level present

others, have symptoms of depression not covered by the NPI.

\section{Use of sedatives, anxiolytics and anti-dementia drugs}

The most prevalent type of psychotropic drugs used in this sample were sedatives, with a prevalence of approximately $21-23 \%$ at the assessments. The prevalence of use of sedatives was lower in a population-based study of assumingly healthier community-dwelling older adults than the prevalence found in our study [71], but these samples are difficult to compare. For example, in the present study, use of sedatives at one time-point was associated with lower P-ADL function, poor physical health (low GMHR) and higher age, as found in other studies [72, 73].

The prevalence of anxiolytics remained quite stable at all three assessments (approximately 9-12\%). The use of anxiolytics at one time-point was found to be associated with female gender and higher affective sub-syndrome of NPI at the same time-point, but persistent use of anxiolytics was not associated with affective sub-syndrome at the first time-point. Thus, this may indicate that change in affective sub-syndrome of NPI have importance for discontinuation of anxiolytics in the present study.

The prevalence of anti-dementia drugs was found to be low. However, some participants without a dementia diagnosis were using anti-dementia drugs. The explanation may be that the general practitioner usually prescribing the drugs, may prescribe the drugs because of suspicion of dementia [74]. The prevalence of anti-dementia drug use was in the descriptive analysis higher in nursing home residents, but we did not explore the use of anti-dementia drugs further, thus the findings may be due to the fact that also the prevalence of dementia was higher in nursing homes.

\section{Strengths and limitations}

This study has significant strengths. Firstly, all nurses participating in the data collection were trained in a 2-day educational course prior to the first data collection and further one-day repetition before the second and last assessment to ensure adequate knowledge prior to the data collection. Secondly, a large sample size made it 
Table 5 OR for use of each category of psychotropic drugs at one time-point given use of the same drug at the previous time point with covariates measured at the same previous time-point

\begin{tabular}{|c|c|c|c|c|c|c|c|c|}
\hline \multirow[t]{3}{*}{ Variable } & \multicolumn{4}{|c|}{ Antipsychotics $(N=954)$} & \multicolumn{4}{|c|}{ Antidepressants $(\mathrm{N}=954)$} \\
\hline & \multicolumn{2}{|l|}{ Unadjusted } & \multicolumn{2}{|l|}{ Adjusted } & \multicolumn{2}{|l|}{ Unadjusted } & \multicolumn{2}{|l|}{ Adjusted } \\
\hline & OR $(95 \% \mathrm{Cl})$ & $p$-value & OR $(95 \% \mathrm{Cl})$ & $p$-value & OR $(95 \% \mathrm{Cl})$ & p-value & OR $(95 \% \mathrm{Cl})$ & p-value \\
\hline \multicolumn{9}{|l|}{ Assessed at previous time-point } \\
\hline CDR-SoB & $1.14(1.04 ; 1.24)$ & 0.005 & $1.04(0.91 ; 1.19)$ & $0.582^{4}$ & $1.13(1.07 ; 1.19)$ & $<0.001$ & $1.04(0.96 ; 1.13)$ & $0.346^{5}$ \\
\hline GMHR (Good/fairly good) & $0.56(0.26 ; 1.22)$ & 0.145 & $1.08(0.43 ; 2.73)$ & $0.866^{9}$ & $0.91(0.59 ; 1.40)$ & 0.668 & $1.37(0.84 ; 2.23)$ & $0.214^{6}$ \\
\hline PSMS & $1.17(1.07 ; 1.28)$ & 0.001 & $1.13(0.99 ; 1.29)$ & $0.057^{2}$ & $1.13(1.07 ; 1.20)$ & $<0.001$ & $1.10(1.01 ; 1.19)$ & $0.025^{3}$ \\
\hline NPI Agitation sub-syndrome & $1.07(1.00 ; 1.14)$ & 0.049 & $1.03(0.94 ; 1.13)$ & $0.557^{5}$ & $1.05(1.00 ; 1.10)$ & 0.037 & $0.97(0.91 ; 1.02)$ & $0.248^{8}$ \\
\hline NPI Psychosis sub-syndrome & $1.10(0.97 ; 1.25)$ & 0.148 & $0.98(0.79 ; 1.22)$ & $0.867^{10}$ & $1.12(1.02 ; 1.23)$ & 0.018 & $1.04(0.93 ; 1.17)$ & $0.482^{10}$ \\
\hline NPI Affective sub-syndrome & $1.03(0.96 ; 1.09)$ & 0.410 & $1.01(0.92 ; 1.11)$ & $0.833^{8}$ & $1.09(1.05 ; 1.13)$ & $<0.001$ & $1.08(1.03 ; 1.13)$ & $0.001^{2}$ \\
\hline Married & $1.46(0.64 ; 3.30)$ & 0.365 & $0.84(0.30 ; 2.39)$ & $0.748^{7}$ & $0.69(0.40 ; 1.20)$ & 0.186 & $0.71(0.38 ; 1.33)$ & $0.287^{7}$ \\
\hline Entry to $\mathrm{NH}$ & $3.57(1.11 ; 11.50)$ & 0.033 & $1.67(0.40 ; 7.01)$ & $0.488^{6}$ & $3.54(1.64 ; 7.68)$ & 0.001 & $2.52(1.02 ; 6.26)$ & $0.047^{4}$ \\
\hline \multicolumn{9}{|l|}{ Assessed at baseline } \\
\hline Age & $0.92(0.86 ; 0.98)$ & 0.016 & $0.91(0.84 ; 0.99)$ & $0.034^{1}$ & $0.95(0.91 ; 0.99)$ & 0.021 & $0.93(0.89 ; 0.97)$ & $0.001^{1}$ \\
\hline \multirow[t]{4}{*}{ Males } & $2.42(1.12 ; 5.22)$ & 0.025 & $2.10(0.80 ; 5.53)$ & $0.133^{3}$ & $0.68(0.39 ; 1.16)$ & 0.153 & $0.74(0.40 ; 1.35)$ & $0.319^{9}$ \\
\hline & \multicolumn{4}{|c|}{ Anxiolytics ( $N=954)$} & \multicolumn{4}{|c|}{ Sedatives $(N=954)$} \\
\hline & \multicolumn{2}{|l|}{ Unadjusted } & \multicolumn{2}{|l|}{ Adjusted } & \multicolumn{2}{|l|}{ Unadjusted } & \multicolumn{2}{|l|}{ Adjusted } \\
\hline & OR $(95 \% \mathrm{Cl})$ & $p$-value & OR $(95 \% \mathrm{Cl})$ & $p$-value & OR $(95 \% \mathrm{Cl})$ & $p$-value & OR $(95 \% \mathrm{Cl})$ & p-value \\
\hline \multicolumn{9}{|l|}{ Assessed at previous time-point } \\
\hline CDR-SoB & $1.13(1.06 ; 1.21)$ & $<0.001$ & $1.05(0.94 ; 1.17)$ & $0.377^{4}$ & $1.05(0.99 ; 1.11)$ & 0.074 & $0.99(0.92 ; 1.08)$ & $0.849^{9}$ \\
\hline GMHR (Good/fairly good) & $0.80(0.43 ; 1.51)$ & 0.493 & $1.05(0.51 ; 2.13)$ & $0.901^{9}$ & $0.64(0.41 ; 0.98)$ & 0.039 & $0.70(0.44 ; 1.12)$ & $0.137^{3}$ \\
\hline PSMS & $1.15(1.06 ; 1.24)$ & $<0.001$ & $1.13(1.01 ; 1.26)$ & $0.031^{2}$ & $1.09(1.03 ; 1.16)$ & 0.002 & $1.08(0.99 ; 1.17)$ & $0.056^{2}$ \\
\hline NPI Agitation sub-syndrome & $1.05(0.99 ; 1.11)$ & 0.089 & $0.98(0.91 ; 1.06)$ & $0.665^{8}$ & $1.02(0.97 ; 1.07)$ & 0.474 & $1.01(0.95 ; 1.07)$ & $0.813^{10}$ \\
\hline NPI Psychosis sub-syndrome & $1.13(1.01 ; 1.27)$ & 0.029 & $1.06(0.92 ; 1.22)$ & $0.422^{6}$ & $1.01(0.91 ; 1.12)$ & 0.892 & $0.96(0.85 ; 1.10)$ & $0.576^{7}$ \\
\hline NPI Affective sub-syndrome & $1.07(1.02 ; 1.13)$ & 0.003 & $1.04(0.98 ; 1.10)$ & $0.167^{3}$ & $1.03(0.99 ; 1.07)$ & 0.123 & $1.02(0.98 ; 1.07)$ & $0.367^{5}$ \\
\hline Married & $0.91(0.43 ; 1.93)$ & 0.801 & $1.52(0.65 ; 3.59)$ & $0.337^{5}$ & $0.77(0.45 ; 1.32)$ & 0.336 & $0.77(0.43 ; 1.40)$ & $0.396^{4}$ \\
\hline Entry to $\mathrm{NH}$ & $1.63(0.50 ; 5.36)$ & 0.420 & $0.67(0.17 ; 2.60)$ & $0.561^{7}$ & $1.29(0.51 ; 3.23)$ & 0.589 & $0.77(0.28 ; 2.13)$ & $0.608^{8}$ \\
\hline \multicolumn{9}{|l|}{ Assessed at baseline } \\
\hline Age & $1.02(0.96 ; 1.09)$ & 0.438 & $1.00(0.94 ; 1.07)$ & $0.978^{10}$ & $1.07(1.02 ; 1.12)$ & 0.003 & $1.07(1.02 ; 1.12)$ & $0.005^{1}$ \\
\hline Males & $0.23(0.08 ; 0.69)$ & 0.009 & $0.18(0.05 ; 0.61)$ & $0.006^{1}$ & $1.00(0.61 ; 1.66)$ & 0.988 & $1.17(0.67 ; 2.06)$ & $0.585^{6}$ \\
\hline
\end{tabular}

CDR-SoB Clinical Dementia Rating - Sum of Boxes

GMHR General Medical Health Rating, PSMS Physical Self-Maintenance Scale, NPI Neuropsychiatric Inventory, NH Nursing Home

possible to adjust for many potential covariates. Lastly, it is a strength that the participants included in this study came from municipalities covering a larger part of the country and municipalities with both rural and urban areas. However, because inclusion was not based on a random selection from all parts of Norway, we cannot guarantee that the sample is representative for all older adults in Norway receiving domiciliary care.

The study has some limitations of importance. Firstly, participants were not randomly selected, and several refused to participate at baseline. In addition, our study included an expected frailer part of the community-dwelling older adults, as opposed to those without any kind of domiciliary care needs. Another inclusion criterion was that the participants had to have a next of kin that saw them at least once every week. Thus, cautions with regard generalizations of study results should be taken. Secondly, we have information about use of psychotropic drugs only from the medical record. It was not cross-checked with the Norwegian Prescription Database [65], the patient or the next of kin whether the drug still was prescribed and taken. Furthermore, we lack information about length of use and attempts of discontinuation between assessment points. Thirdly, at baseline some of the participants were already regular users of domiciliary care while others were recruited when first enrolled in the domiciliary care services. Lastly, the results of 


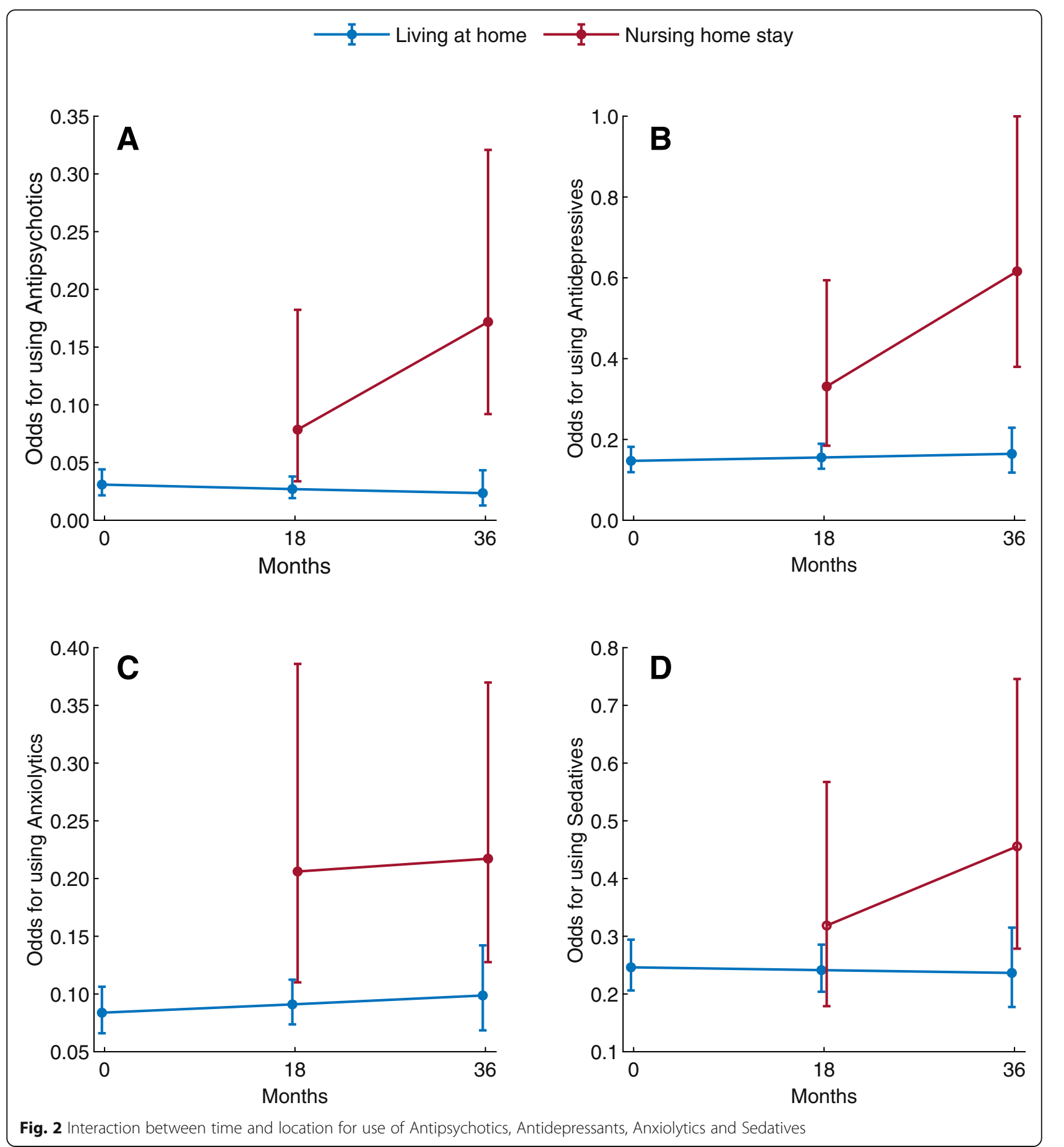

persistent use of psychotropic drugs, particularly antipsychotics, might suffer from low power, especially in the adjusted models.

\section{Clinical implications}

It's been known that the use of psychotropic drugs, especially antipsychotic drugs, among nursing home residents has been extensive. In Norway, as well as internationally, one has been working towards prescribing less psychotropic drugs in nursing homes. We have not had the same focus on the use of psychotropic drugs among older adults living at home, with and without dementia. Our study may contribute to broaden the focus to also include older adults, living at home with a need of domiciliary care. In such cases the GP has the responsibility to follow up the drug use, and also 
communication with the provider of domiciliary care so that e.g. follow-up of possible side-effects from discontinuation can be observed and registered. Less prescription of psychotropic drugs, may also introduce better treatment alternatives for NPS in older adults, e.g. milieu therapy.

\section{Conclusion}

The prevalence and persistency of psychotropic drugs in older adults receiving domiciliary care at inclusion was high. The use of antipsychotics was higher in those with dementia than in those without dementia at all assessment time-points, and a high proportion of those using antipsychotics used traditional antipsychotics. Nursing home admission during follow-up was associated with increased odds for use of both antipsychotics and antidepressants at the last follow-up. Monitoring effects and adverse effects of psychotropic drugs is an important part of the treatment, and discontinuation of drugs should be considered regularly.

\section{Additional file}

Additional file 1: Tables S1, S2_1, S2_2, S2_3 and S2_4. Table S1

shows effect on location on use of psychotropic drugs with covariates measured at baseline or at the same time-point. Table S2_1, S2_2, S2_3 and $\mathbf{S 2} \mathbf{4}$ shows interpretation of the interaction term in the model for use of Antipsychotics, Antidepressants, Anxiolytics and Sedatives, respectively. (DOCX $47 \mathrm{~kb})$

\section{Abbreviations}

A1: Assessment at baseline; A2: Assessment 2, 18 months after baseline; A3: Assessment 3, 36 months after baseline; AIC: Akaike's Information Criteria; ATC: Anatomical Therapeutic Chemical; CDR: Clinical Dementia Rating; CDRSoB: Clinical Dementia Rating - Sum of Boxes; Cl: Confidence Interval; GMHR: General Medical Health Rating; N: Number; NH: Nursing Home; NPI: Neuropsychiatric Inventory; NPS: Neuropsychiatric symptoms; OR: Odds Ratio; P-ADL: Personal Activities of Daily Living; PSMS: Physical Self-

Maintenance Scale; SAS: Statistical Analysis Software; SD: Standard Deviation; SPSS: Statistical Package for the Social Sciences

\section{Acknowledgements}

We wish to acknowledge the valuable personal health information contributed by the participating individuals, and the medical staff who performed the data collection.

\section{Funding}

Data collection was financed by the Norwegian Directorate of Health and Innlandet Hospital trust.

\section{Availability of data and materials}

The data belong to the Centre for old age psychiatry research, Innlandet Hospital trust, and will not be shared due to The Regional Committee for Medical and Health Research Ethics and Norwegian regulations.

\section{Authors' contributions}

MTL and MA have contributed equally throughout the process of preparing the manuscript. They conducted the first analysis, interpreted the findings and drafted the manuscript. ASH had the research idea, and participated in the first analysis, interpretation of the findings and drafting of the manuscript. SB was responsible for the study design and the data collection. JSB conducted the main statistical analyses. All authors participated in the interpretation of the study results and in editing the manuscript, and have read and approved the final manuscript.

\section{Ethics approval and consent to participate}

The project was approved by the Regional Committee for Medical and Health Research Ethics for Eastern Norway, the Norwegian Social Science Data Services and the Directorate for Health and Social Affairs. Written information about the study was given to the participants and their next of kin. A written informed consent was collected from both the participant and their next of kin prior to the baseline interview. For those participants not capable of giving informed consent, consent was given on their behalf by their next of kin. These procedures were recommended by the Regional Committee for Medical and Health Research Ethics for Eastern Norway, the Norwegian Social Science Data Services and the Directorate for Health and Social Affairs.

\section{Consent for publication}

Not applicable.

\section{Competing interests}

The authors declare that they have no competing interests.

\section{Publisher's Note}

Springer Nature remains neutral with regard to jurisdictional claims in published maps and institutional affiliations.

\section{Author details}

'Department of Public Health and Nursing, Norwegian University of Science and Technology (NTNU), Postbox 8905, N-7491 Trondheim, Norway. ${ }^{2}$ Centre for Old Age Psychiatric Research, Innlandet Hospital Trust, Ottestad, Norway; Norwegian National Advisory Unit on Ageing and Health, Vestfold Hospital Trust, Tønsberg, Norway. ${ }^{3}$ Institute of Clinical Medicine, University of Oslo, Norway; Health Services Research Unit, Akershus University Hospital, Lørenskog, Norway; Centre for Old Age Psychiatric Research, Innlandet Hospital Trust, Ottestad, Norway. ${ }^{4}$ General Practice Research Unit, Department of Public Health and Nursing, Faculty of Medicine and Health Sciences, Norwegian University of Science and Technology (NTNU), Trondheim, Norway; St Olavs University Hospital, Trondheim, Norway; Norwegian National Advisory Unit on Ageing and Health, Vestfold Hospital Trust, Tønsberg, Norway.

Received: 8 March 2018 Accepted: 2 April 2019

Published online: 25 April 2019

\section{References}

1. Jyrkka J, Enlund H, Korhonen MJ, Sulkava R, Hartikainen S. Patterns of drug use and factors associated with polypharmacy and excessive polypharmacy in elderly persons: results of the Kuopio $75+$ study: a cross-sectional analysis. Drugs Aging. 2009;26(6):493-503.

2. Hartikainen S, Mantyselka P, Louhivuori-Laako K, Enlund H, Sulkava R. Concomitant use of analgesics and psychotropics in home-dwelling elderly people-Kuopio 75 + study. Br J Clin Pharmacol. 2005;60(3):306-10.

3. Simoni-Wastila L, Yang HK. Psychoactive drug abuse in older adults. Am J Geriatr Pharmacother. 2006:4(4):380-94.

4. Frydenlund R, Oslo R. Older adults, alcohol and use of medications: a summary of knowledge [eldre, alkohol og legemiddelbruk: en kunnskapsoppsummering]. Kompetansesenter rus - Oslo Rusmiddeletaten, Oslo Kommune: Oslo; 2011.

5. Midfflå JM. Universitetet i T: use of anxiolytics and hypnotics in older adults: prescription database 2004 and 2005 [Bruk av anxiolytika og hypnotika til eldre : reseptregisteret 2004 og 2005]. In. Tromsø: Universitetet i Tromsø; 2007.

6. Haasum Y, Fastbom J, Fratiglioni L, Kareholt I, Johnell K. Pain treatment in elderly persons with and without dementia: a population-based study of institutionalized and home-dwelling elderly. Drugs Aging. 2011;28(4):283-93.

7. Taipale H, Koponen M, Tanskanen A, Tolppanen AM, Tiihonen J, Hartikainen S. High prevalence of psychotropic drug use among persons with and without Alzheimer's disease in Finnish nationwide cohort. Eur Neuropsychopharmacol. 2014;24(11):1729-37.

8. Wergeland JN, Selbaek G, Hogset LD, Soderhamn U, Kirkevold O. Dementia, neuropsychiatric symptoms, and the use of psychotropic drugs among 
older people who receive domiciliary care: a cross-sectional study. Int Psychogeriatr. 2014;26(3):383-91.

9. Gulla C, Selbaek G, Flo E, Kjome R, Kirkevold O, Husebo BS. Multipsychotropic drug prescription and the association to neuropsychiatric symptoms in three Norwegian nursing home cohorts between 2004 and 2011. BMC Geriatr. 2016;16:115.

10. Chan DC, Kasper JD, Black BS, Rabins PV. Clinical diagnosis of dementia, not presence of behavioral and psychological symptoms, is associated with psychotropic use in community-dwelling elders classified as having dementia. J Geriatr Psychiatry Neurol. 2007;20(1):50-7.

11. Stock KJ, Amuah JE, Lapane KL, Hogan DB, Maxwell CJ. Prevalence of, and resident and facility characteristics associated with antipsychotic use in assisted living vs. long-term care facilities: a cross-sectional analysis from Alberta, Canada. Drugs Aging. 2017;34(1):39-53.

12. Alanen HM, Finne-Soveri $H$, Noro A, Leinonen E. Use of antipsychotics among nonagenarian residents in long-term institutional care in Finland. Age Ageing. 2006;35(5):508-13.

13. Kamble P, Chen H, Sherer J, Aparasu RR. Antipsychotic drug use among elderly nursing home residents in the United States. Am J Geriatr Pharmacother. 2008;6(4):187-97.

14. Helvik AS, Saltyte Benth J, Wu B, Engedal K, Selbaek G. Persistent use of psychotropic drugs in nursing home residents in Norway. BMC Geriatr. 2017;17(1):52.

15. Madhusoodanan S, Ting MB. Pharmacological management of behavioral symptoms associated with dementia. World J Psychiatry. 2014;4(4):72-9.

16. American Geriatrics S. American Association for Geriatric P: consensus statement on improving the quality of mental health care in U.S. nursing homes: management of depression and behavioral symptoms associated with dementia. J Am Geriatr Soc. 2003;51(9):1287-98.

17. By the American Geriatrics Society Beers Criteria Update Expert P. American Geriatrics society 2015 updated beers criteria for potentially inappropriate medication use in older adults. J Am Geriatr Soc. 2015;63(11):2227-46.

18. Gustafsson M, Karlsson S, Lovheim H. Inappropriate long-term use of antipsychotic drugs is common among people with dementia living in specialized care units. BMC Pharmacol Toxicol. 2013;14:10.

19. Young SL, Taylor M, Lawrie SM. "first do no harm." a systematic review of the prevalence and management of antipsychotic adverse effects. J Psychopharmacol. 2015;29(4):353-62.

20. Correll CU, Joffe BI, Rosen LM, Sullivan TB, Joffe RT. Cardiovascular and cerebrovascular risk factors and events associated with second-generation antipsychotic compared to antidepressant use in a non-elderly adult sample: results from a claims-based inception cohort study. World Psychiatry. 2015;14(1):56-63.

21. Mehta S, Johnson ML, Chen H, Aparasu RR. Risk of cerebrovascular adverse events in older adults using antipsychotic agents: a propensity-matched retrospective cohort study. J Clin Psychiatry. 2010;71(6):689-98.

22. Cox CA, van Jaarsveld HJ, Houterman S, van der Stegen JC, Wasylewicz AT, Grouls RJ, van der Linden CM. Psychotropic drug prescription and the risk of falls in nursing home residents. J Am Med Dir Assoc. 2016.

23. Du Y, Wolf IK, Knopf H. Association of psychotropic drug use with falls among older adults in Germany. Results of the German Health Interview and Examination Survey for Adults 2008-2011 (DEGS1). PloS one. 2017;12(8): e0182432.

24. Kales HC, Valenstein M, Kim HM, McCarthy JF, Ganoczy D, Cunningham F, Blow FC. Mortality risk in patients with dementia treated with antipsychotics versus other psychiatric medications. Am J Psychiatry. 2007;164(10):1568-76 quiz 1623.

25. Gill SS, Bronskill SE, Normand SL, Anderson GM, Sykora K, Lam K, Bell CM, Lee $P E$, Fischer HD, Herrmann N, et al. Antipsychotic drug use and mortality in older adults with dementia. Ann Intern Med. 2007;146(11):775-86.

26. Divac N, Prostran M, Jakovcevski I, Cerovac N. Second-generation antipsychotics and extrapyramidal adverse effects. Biomed Res Int. 2014;2014:656370.

27. Ballard C, Creese B, Corbett A, Aarsland D. Atypical antipsychotics for the treatment of behavioral and psychological symptoms in dementia, with a particular focus on longer term outcomes and mortality. Expert Opin Drug Saf. 2011;10(1):35-43.

28. Lee SH, Hsu WT, Lai CC, Esmaily-Fard A, Tsai YW, Chiu CC, Wang J, Chang SS, Lee CC. Use of antipsychotics increases the risk of fracture: a systematic review and meta-analysis. Osteoporos Int. 2017;28(4):1167-78.

29. Kvelde T, Lord SR, Close JC, Reppermund S, Kochan NA, Sachdev P, Brodaty $\mathrm{H}$, Delbaere K. Depressive symptoms increase fall risk in older people, independent of antidepressant use, and reduced executive and physical functioning. Arch Gerontol Geriatr. 2015;60(1):190-5.

30. Marcum ZA, Perera S, Thorpe JM, Switzer GE, Castle NG, Strotmeyer ES, Simonsick EM, Ayonayon HN, Phillips CL, Rubin S, et al. Antidepressant use and recurrent falls in community-dwelling older adults: findings from the health ABC study. Ann Pharmacother. 2016;50(7):525-33.

31. van Strien AM, Koek HL, van Marum RJ, Emmelot-Vonk MH. Psychotropic medications, including short acting benzodiazepines, strongly increase the frequency of falls in elderly. Maturitas. 2013;74(4):357-62.

32. Nuutinen M, Leskela RL, Suojalehto E, Tirronen A, Komssi V. Development and validation of classifiers and variable subsets for predicting nursing home admission. BMC Med Inform Decis Mak. 2017;17(1):39.

33. Gaugler JE, Duval S, Anderson KA, Kane RL. Predicting nursing home admission in the U.S: a meta-analysis. BMC Geriatr. 2007;7:13.

34. Luppa M, Luck T, Matschinger H, Konig HH, Riedel-Heller SG. Predictors of nursing home admission of individuals without a dementia diagnosis before admission - results from the Leipzig longitudinal study of the aged (LEILA 75+). BMC Health Serv Res. 2010;10:186.

35. Nygaard HA, Albrektsen G. Risk factors for admission to a nursing home. A study of elderly people receiving home nursing. Scand J Prim Health Care. 1992;10(2):128-33.

36. Nygaard HA. Duration of drug treatment in nursing homes. Tidsskr Nor Laegeforen. 2001;121(12):1469-71.

37. Maguire A, Hughes C, Cardwell C, O'Reilly D. Psychotropic medications and the transition into care: a national data linkage study. J Am Geriatr Soc. 2013;61(2):215-21.

38. Jacobs JM, Maaravi Y, Cohen A, Bursztyn M, Ein-Mor E, Stessman J. Changing profile of health and function from age 70 to 85 years. Gerontology. 2012;58(4):313-21.

39. Lyketsos CG, Galik E, Steele C, Steinberg M, Rosenblatt A, Warren A, Sheppard JM, Baker A, Brandt J. The general medical health rating: a bedside global rating of medical comorbidity in patients with dementia. J Am Geriatr Soc. 1999:47(4):487-91.

40. Lawton MP, Brody EM. Assessment of older people: self-maintaining and instrumental activities of daily living. Gerontologist. 1969;9(3):179-86.

41. Folstein MF, Folstein SE, McHugh PR. "mini-mental state". A practical method for grading the cognitive state of patients for the clinician. J Psychiatr Res. 1975;12(3):189-98.

42. Shulman Kl. Clock-drawing: is it the ideal cognitive screening test? Int J Geriatr Psychiatry. 2000;15(6):548-61.

43. Jorm AF. The informant questionnaire on cognitive decline in the elderly (IQCODE): a review. Int Psychogeriatr. 2004;16(3):275-93.

44. Hughes CP, Berg L, Danziger WL, Coben LA, Martin RL. A new clinical scale for the staging of dementia. Br J Psychiatry. 1982;140:566-72.

45. O'Bryant SE, Waring SC, Cullum CM, Hall J, Lacritz L, Massman PJ, Lupo PJ, Reisch JS, Doody R. Texas Alzheimer's research C: staging dementia using clinical dementia rating scale sum of boxes scores: a Texas Alzheimer's research consortium study. Arch Neurol. 2008;65(8):1091-5.

46. Engedal $K$, Haugen P, Gilje K, Laake P. Efficacy of short mental tests in the detection of mental impairment in old age. Compr Gerontol A. 1988;2(2):87-93.

47. Nesset M, Kersten H, Ulstein ID. Brief tests such as the clock drawing test or Cognistat can be useful predictors of Conversion from MCl to dementia in the clinical assessment of outpatients. Dement Geriatr Cogn Dis Extra. 2014;4(2):263-70.

48. Engedal K, Haugen PK. The prevalence of dementia in a sample of elderly norwegians. Int J Geriatr Psychiatry. 1993;8(7):565-70.

49. Cummings JL. The neuropsychiatric inventory: assessing psychopathology in dementia patients. Neurology. 1997:48(5 Suppl 6):S10-6.

50. Selbaek G, Kirkevold O, Sommer OH, Engedal K. The reliability and validity of the Norwegian version of the neuropsychiatric inventory, nursing home version (NPI-NH). Int Psychogeriatr. 2008;20(2):375-82.

51. The International Classification of Diseases (ICD). WHO. 2008, [https:// icd.who.int/browse10/2008/en] Accessed November 27th 2017.

52. Akaike H. A new look at the statistical model identification. Autom Control IEEE Trans. 1974;19(6): :16-23.

53. Schulze J, Glaeske G, van den Bussche H, Kaduszkiewicz H, Koller D, Wiese B, Hoffmann F. Prescribing of antipsychotic drugs in patients with dementia: a comparison with age-matched and sex-matched non-demented controls. Pharmacoepidemiol Drug Saf. 2013;22(12):1308-16.

54. Laitinen ML, Bell JS, Lavikainen P, Lonnroos E, Sulkava R, Hartikainen S. Nationwide study of antipsychotic use among community-dwelling persons with Alzheimer's disease in Finland. Int Psychogeriatr. 2011;23(10):1623-31. 
55. Jackson JW, VanderWeele TJ, Viswanathan A, Blacker D, Schneeweiss S. The explanatory role of stroke as a mediator of the mortality risk difference between older adults who initiate first- versus second-generation antipsychotic drugs. Am J Epidemiol. 2014;180(8):847-52.

56. Jeste DV, Rockwell E, Harris MJ, Lohr JB, Lacro J. Conventional vs. newer antipsychotics in elderly patients. Am J Geriatr Psychiatry. 1999;7(1):70-6.

57. Rattinger GB, Burcu M, Dutcher SK, Chhabra PT, Rosenberg PB, SimoniWastila L, Franey CS, Walker LD, Zuckerman IH. Pharmacotherapeutic management of dementia across settings of care. J Am Geriatr Soc. 2013; 61(5):723-33.

58. Meleis Al, Sawyer LM, Im EO, Hilfinger Messias DK, Schumacher K. Experiencing transitions: an emerging middle-range theory. ANS Adv Nurs Sci. 2000;23(1):12-28.

59. Hvalvik S. Ase Reierson I: Transition from self-supported to supported living: Older people's experiences. Int J Qual Stud Health Well-being. 2011;6(4).

60. Reus VI, Fochtmann LJ, Eyler AE, Hilty DM, Horvitz-Lennon M, Jibson MD, Lopez OL, Mahoney J, Pasic J, Tan ZS, et al. The American Psychiatric Association practice guideline on the use of antipsychotics to treat agitation or psychosis in patients with dementia. Am J Psychiatry. 2016; 173(5):543-6.

61. Masopust J, Protopopova D, Valis M, Pavelek Z, Klimova B. Treatment of behavioral and psychological symptoms of dementias with psychopharmaceuticals: a review. Neuropsychiatr Dis Treat. 2018;14:1211-20.

62. Tampi RR, Tampi DJ, Balachandran S, Srinivasan S. Antipsychotic use in dementia: a systematic review of benefits and risks from meta-analyses. Ther Adv Chronic Dis. 2016;7(5):229-45.

63. Van Leeuwen E, Petrovic M, van Driel ML, De Sutter Al, Vander Stichele R, Declercq T, Christiaens T. Withdrawal versus continuation of long-term antipsychotic drug use for behavioural and psychological symptoms in older people with dementia. Cochrane Database Syst Rev. 2018;3:CD007726.

64. Declercq T, Petrovic M, Azermai M, Vander Stichele R, De Sutter Al, van Driel ML, Christiaens T. Withdrawal versus continuation of chronic antipsychotic drugs for behavioural and psychological symptoms in older people with dementia. Cochrane Database Syst Rev. 2013;3:CD007726.

65. Norwegian Prescription Database [Nasjonalt reseptbasert legemiddelregister]. Norwegian Institute of Public Health. 2016, [ http:// www.norpd.no ]. Accessed 22 Nov 2017.

66. Harris MG, Burgess PM, Pirkis J, Siskind D, Slade T, Whiteford HA. Correlates of antidepressant and anxiolytic, hypnotic or sedative medication use in an Australian community sample. Aust N Z J Psychiatry. 2011;45(3):249-60.

67. Weissman J, Meyers BS, Ghosh S, Bruce ML. Demographic, clinical, and functional factors associated with antidepressant use in the home healthcare elderly. Am J Geriatr Psychiatry. 2011;19(12):1042-5.

68. Steinberg M, Shao H, Zandi P, Lyketsos CG, Welsh-Bohmer KA, Norton MC, Breitner JC, Steffens DC, Tschanz JT, Cache County I. Point and 5-year period prevalence of neuropsychiatric symptoms in dementia: the Cache County study. Int J Geriatr Psychiatry. 2008;23(2):170-7.

69. Nelson JC, Devanand DP. A systematic review and meta-analysis of placebocontrolled antidepressant studies in people with depression and dementia. J Am Geriatr Soc. 2011;59(4):577-85.

70. Bergh S, Selbaek G, Engedal K. Discontinuation of antidepressants in people with dementia and neuropsychiatric symptoms (DESEP study): double blind, randomised, parallel group, placebo controlled trial. BMJ. 2012;344:e1566.

71. Tevik K, Selbaek G, Engedal K, Seim A, Krokstad S, Helvik AS. Use of alcohol and drugs with addiction potential among older women and men in a population-based study. The Nord-Trondelag Health Study 2006-2008 (HUNT3). PLoS One. 2017;12(9):e0184428.

72. Kjosavik SR, Ruths S, Hunskaar S. Psychotropic drug use in the Norwegian general population in 2005: data from the Norwegian prescription database. Pharmacoepidemiol Drug Saf. 2009;18(7):572-8.

73. Blumstein T, Benyamini Y, Chetrit A, Mizrahi EH, Lerner-Geva L. Prevalence and correlates of psychotropic medication use among older adults in Israel: cross-sectional and longitudinal findings from two cohorts a decade apart. Aging Ment Health. 2012;16(5):636-47.

74. Diaz E, Kumar BN, Engedal K. Immigrant patients with dementia and memory impairment in primary health care in Norway: a national registry study. Dement Geriatr Cogn Disord. 2015;39(5-6):321-31.

\section{Ready to submit your research? Choose BMC and benefit from:}

- fast, convenient online submission

- thorough peer review by experienced researchers in your field

- rapid publication on acceptance

- support for research data, including large and complex data types

- gold Open Access which fosters wider collaboration and increased citations

- maximum visibility for your research: over $100 \mathrm{M}$ website views per year

At $\mathrm{BMC}$, research is always in progress.

Learn more biomedcentral.com/submissions 